\title{
Presentation of Two New Empirical Equations for Point-Centered Quarter Method for Estimating Trees Density in the Forest
}

Reza Hossein Haidari ( $\nabla$ rhhaidari@razi.ac.ir)

Razi University

Research

Keywords: density, distance methods, new formulas, Oak, PCQ method, Zagros

Posted Date: August 5th, 2020

DOI: https://doi.org/10.21203/rs.3.rs-46899/v1

License: (c) (1) This work is licensed under a Creative Commons Attribution 4.0 International License.

Read Full License 


\section{Abstract}

7 Background and objectives: The point-centered quarter(PCQ) method is one of the distance

8 sampling methods. Previously, researchers such as Cottam and Curtis (1954), Pollard(1971),

9 and Haidari et al. (2008) introduced three equations to the estimation of plant density using

10 the above method. The objective of this research includes developing two new formula for the

11 estimation of tree density with the PCQ method, which is not biased toward the tree distribution

12 pattern.

13 Materials and methods: In this study, 40 circular sample plots (1000 $\mathrm{m}^{2}$ as the real state) and

14 PCQ method were measured via a systematic random sampling design $(100 \mathrm{~m} \times 100 \mathrm{~m})$ in the

15 educational research forest at Razi University in Dalahoo Mountain in Kermanshah province.

16 Later, through the mentioned formulas, forest stand density was calculated. Then, the obtained

17 density with different formulas of the PCQ method with the circular plot in the spatial pattern

18 of various types (uniform, random, and cluster) was compared in terms of accuracy and 19 precision.

20 Results: The results showed that two new empirical equations for estimating the density of

21 trees in forest stand were more appropriate than the previous equations in terms of accuracy

22 and precision.

23 Conclusion: The new equations have the following important characteristics: Firstly,

24 they are less dependence on the tree distribution pattern than other equations are, and 25 secondly, the number of trees per area unit can be calculated for each sampling point like 
26 the equation used for the sample plot methods. Finally, it is suggested to use the new

27 equations for other forests and also other vegetation, such as the grasslands and

28 scrublands.

30 Key words: density, distance methods, new formulas, Oak, PCQ method, Zagros.

32 Introduction

33 Density is one of the most remarkable vegetation traits (Bonham, 2013). Sampling methods

34 with plot-based and plot-less (distance methods) are used to estimate the density of the trees.

35 The main objective of sampling is to develop an accurate and precise survey of plant

36 communities' characteristics in ecological studies (Borges Silva et al. 2017). Distance

37 sampling methods have been used to measure plant density since the 1950s (Bonham, 2013).

38 Most distance sampling methods have more than one empirical formula.

39 The development of non-

40 dimensions and fixed shapes is aimed at increasing inventory speed, reducingsampling time

41 and thus keeping running costs low and achieving correct accuracy (Namiranian, 2010).Spati

42 al patterns are influenced by vegetation density estimation using distance sampling methods.

43 While the density estimation by distance methods is not biased if plants and animals have a

44 random distribution pattern, it will be biased if the plants and animals have a cluster pattern.

45 Therefore, the distribution pattern of individuals should be determined using distance methods

46 before estimating population density (Krebs 1989). The bias is dependent on the plan

47 (inventory network, number of points, etc.) or the estimator. When the distance among sample

48 points and trees or the distance between the trees is low, formulas provide more estimates of

49 quantitative parameters. This can be a significant obstacle to determining the quantitative 50 parameters in low-density forests (Askariet al. 2013). 
51 The point-centered quarter method is one of the distance sampling methods. Stearns (1949)

52 indicated that making the first surveys of government land,the point-centered quarter method,

53 whichwas used by surveyors in the mid-nineteenth century,dates backto a least 150 years ago

54 (Mitchell 2007). Cottam and Curtis (1954) compared the point-centered quarter method to

55 quadrate sampling and empirically derived a formula that could be used to estimate population

56 density from the distance data collected. Cottam and Curtis (1954), Pollard(1971), and Haidari

57 et al.(2008) introduced equations to estimate the density of trees using the above method

58 (Haidari 2008).

59 The studies revealed that the equations introduced by the above researchers would bias the

60 estimated density in most cases, especially when the distribution pattern of trees was arranged

61 or cumulative. Engemanet al. (1994) compared some distance methods together using the

62 Monte Carlo simulation program and found the result biased with Cottam and Curtis (1954)

63 and Pollard(1971) estimators for the PCQ method (Engemanet al. 1994).

64 Haidari's study (2008) indicated that the estimation of trees through the equation introduced

65 by Cottam and Curtis (1954) and Pollard(1971) in the clumped distribution pattern was biased

66 (Haidari et al. 2008). Kianiet al. (2013) also compared some distance methods in

67 Haloxylonammodendron lands of Siahkooh in Yazd, Iran, and found that the equation

68 presented by Cottam and Curtis (1954) and Pollard(1971) estimated the density of shrubs

69 erroneously (Kianiet al. 2013).

70 The objective of this study was to presentnew empirical equations for the point-centered

71 quarter method with less dependence on the plant distribution pattern than previous equations

72 had.

\section{Materials and Methods}

74 The studied area: The area was in the educational research forest at Razi University of

75 Kermanshah in Dalahoo Mountain between Kerend-e Gharb and Sarpol-e Zahab cities in 
76 Kermanshah, Iran (Figure 1).

77 The area of the forest was 16000 hectares. The west, north, east, and south of the forest

78 respectively adjoined Habibvand village, DalahooMountains, Sarmil village, and Kuh-e Nava

79 Mountain. The area is geographically located between latitudes of $34^{\circ} 16^{\prime}$ and $34^{\circ} 30^{\prime}$ north

80 and longitudes of $45^{\circ} 55^{\prime}$ and $46^{\circ} 7^{\prime}$ east. In terms of the topography, the area is mountainous

81 and 760-2400 meters above the sea level. The vegetation of the area is of Quercetumpersicum,

82 and Quercuspersica constituted the dominant species of the forest (Haidari 2006).

83 Methods: Firstly, a 40-hectare area was specified in the educational research forest at Razi

84 University of Kermanshah. Then, 40 sampling points (here 40 samples) were marked and

85 numbered on the ground among the studied community using the statistical record network of

$86100 \times 100 \mathrm{~m}$ and the systematic random recording design.

87 Data calculation

88 On each sampling point, a 10-ar circle sample plot was marked on the ground, and the trees

89 inside the circular plot were counted and recorded. Simultaneous to recording each circle

90 sample plot, another sample was recorded using the point-centered quarter method in a way

91 that its starting point (the sampling point) was the center of the circle sample plot (Figure 2).

92 Point-centered quarter method

93 In this sampling method, four distances were measured (Figure 3). Each sampling point is

94 considered the center of the four quarters (quadrants), with orientation given by the compass

95 line of the traverse. At each point, the closest tree to the point in each of the four quarters

96 around the point is chosen as the sample. Distances are measured from the point to each of the

97 four trees recorded. Once the data were collected, all the data collected in the statistical record

98 forms were fed into the computer, and the following calculations were carried out using SPSS,

99 Excel, and Ecological Methodology (Krebs 2001) software programs.

100 Counting trees per hectare 
101 Firstly, the number of trees per unit of area, hectare, and variance in the number of trees were

102 calculated for circle samples, and the dot diagram of the number of trees per area unit of the

103 circle samples was drawn. In the next step, the density of trees in the 40 samples was calculated

104 using different equations of the point-centered quarter method (table 1).

105 A-Equation suggested by Cottam and Curtis 1954 (reference: Cottam and Curtis 1954)

106 B-Equation suggested by Pollard 1971(reference: Pollard 1971)

107 C- Equation suggested by Haidari et al. 2006(reference: Haidari et al. 2008)

108 D-New Empirical Equations suggested by the author (dalahoo1 and dalahoo2)

109 Calculation of the tree distribution pattern

110 There were various indices to quantify the distribution of natural populations. In this study,

111 the variance/mean ratio $\left(S^{2} / \bar{x}\right)$ was used to determine the tree distribution pattern in the area

112 because the circle samples were considered as the control (base). If the ratio equals one, the

113 spatial distribution will be random; the ratio greater than one will indicate a clumped

114 distribution pattern; and the ratio less than one will show a uniform distribution pattern

115 (Moghadam, 2001). The reason that the circle sample plot method was considered as the base

116 was primarily that the circle method is one of the common methods used for Zagros forests,

117 and secondly that all the trees of 40 samples recorded through the point-centered quarter

118 method were inside the circle samples.

119 Rest of calculations

120 To examine the effect of the tree distribution pattern on the results obtained from estimating

121 the density of trees through different equations of the point-centered quarter (equations of

122 Cottam and Curtis (1954), Pollard(1971), Haidari et al. 2008 and also the new equations) after

123 drawing the dot diagram for the 40 samples in the circle sample method, one sample that had

124 the highest deviation from the mean data was eliminated. For the remaining 39 samples, firstly,

125 the spatial distribution pattern (variance/mean ratio) and, then, the number of trees per hectare 
126 and also the equations of the point-centered quarter method were. The calculation continued

127 until the distribution pattern changed from the clumped pattern (the variance/mean ratio was

1282.150 for all the 40 samples) to the random pattern (the variance/mean ratio was 1.02 for 30

129 samples) followed by the uniform pattern (the variance/mean ratio was zero for four samples).

130 In short, the calculations in A and B steps were carried out for 40, 39, and 38 samples in order

131 followed by 4 sample plots with zero variance/mean ratio (the uniform distribution pattern).

132 Finally, the density calculated with different equations of the point-point method was

133 compared to the one obtained from the 10-ar circle samples as the control (base) regarding the

134 paired t-test and the accuracy(A) criterion $(\mathrm{A} \%= \pm 100[($ Estimated - True $) /$ True $])$ (Southwood\&

135 Henderson, 2000). A summary of the calculations was provided in the result section.

137 Results

138 Tree distribution

139 As shown in Table 2, the trees in the studied area had a clumped distribution pattern because

140 the variance/mean ratio for the 40 circle samples was 2.150 . The tree distribution pattern was

141 also determined for 4-39 samples regarding their variance/mean ratio, and the relevant results

142 are shown in Table 2.

143 Number of trees per hectare

144 Table 2 and Figure 4 show the number of trees estimated per hectare using the circle method

145 and different equations of the point-centered quarter method in different tree distribution

146 patterns (with variance/mean ratio of zero, 1 , and 2.150 respectively for the uniform, random,

147 and clumped patterns).

148 A. Regarding the number of samples (4-40 samples in Table 2), values obtained from 149 different equations of the point-centered quarter method for different tree distribution 150 patterns were compared to those obtained from the circle method (the control) using 
paired t-test (Table 3).

152 B. Values obtained from different equations of the point-centered quarter method were 153 compared to those obtained from the circle method (4-40 samples) regarding the 154 accuracy criterion $(\mathrm{A} \%= \pm 100[($ Estimated - True $) /$ True $])($ Table $2 \&$ Figure 5).

\section{Discussions}

156 The results (Table 2) showed that the trees of the studied forest followed the clumped

157 distribution pattern. This result conformed to that of the studies conducted in relation to Zagros

158 forests by other researchers, such as Haidari (2006), Haidari et al. (2007), Safari (2010), and

159 Askari et al. (2013). As shown in Table 2 and Figure 4, the different equations of the point-

160 centered quarter method produced different estimates of the number of trees per hectare, which

161 was due to the nature of the equations estimating density (estimators). According to Askari et

162 al. (2013), bias depended on the design (the statistical record network, number of points, etc.)

163 or the estimator. In this study, the statistical record network and the number of points were

164 identical for all equations, and only the estimators (equations) were different. Moreover, Krebs

165 (1998) pointed out the evident effect of tree distribution patterns on the results of different

166 equations used for density estimation.

167 According to Figure 4, Haidari et al.'s equation (2008) provided a lower estimate for the 168 density of trees in the clumped, random, and uniform distribution patterns than the circle 169 method (the control) did. Thus, Pollard equation (1971) provided a lower estimate for the 170 density of trees inall kinds of distribution patterns than the circle method did. However, based 171 on Table 2 and Figure 4, the equations introduced by Cottam and Curtis (1954) and new 172 equations (dalahoo1 and dalahoo2) provided values for the density estimated in all patterns 173 (clumped, random, and uniform) similar to those obtained in the circle method (the control), 174 but the best formulas seem to be dalahoo 1 and dalahoo2. This was well confirmed by the results 175 of the statistical test, namely the paired t-test (Table 3), and calculation of the acceptable 
176 accuracy (Figure 4). According to Table 2, the equations that were not highly affected by the

177 changes in the distribution pattern were the dalahoo1 and dalahoo2 equations. Furthermore,

178 according to Southwoodet al. (1999), an equation with \pm 10 accuracy could be used in research

179 procedures (Southwood\& Henderson 2000). Table 2 and Figure 5 also show the estimated

180 density of trees in the range of -5.94 to +4.55 using the dalahoo 2 equation against the 10 -ar

181 circle method. In this respect, it could be argued that the dalahoo2 equation provided

182 acceptable results in terms of the accuracy criterion.

183 Based on the equations presented in this study,it appears that the point-centered quarter

184 technique of the distance sampling method can be used for Zagros forests instead of the 10-ar

185 circle sample plot method based on the results of this study; characteristics of Zagros protected

186 forests (that are mountainous in terms of topography and usually with a low density of trees);

187 the point that "when sampling of a piece of land is difficult or too costly (in mountainous lands

188 or forests with low density), distance sampling methods are more appropriate (Shale et al.

189 2003; Picard et al. 2005; \&Kianiet al. 2013)"; and the tree distribution pattern in the studied

190 area that is usually clumped according to the studies conducted in these forests. The reason is

191 that the point-centered quarter method is performed faster than the circle method and takes a

192 much shorter time. The point-centered quarter method using the new equations can largely

193 reduce the costs of statistical recording in forests. The new equations have the following

194 important characteristics:

195 Firstly, they are less dependent on the tree distribution pattern than other equations, and

196 secondly, the number of trees per area unit can be measured for each sampling point like the

197 equation used for the sample plot methods.

198

199

200 Declarations 
201 Acknowledgments

202 I thank research deputy of the Razi University for assistance in the field.

203 Funding

204 This study was funded by the research deputy of the Razi University.

205 Availability of data and materials

206 The datasets used and analyzed during the current study are available from the

207 corresponding author on reasonable request.

208 Ethics approval and consent to participate

209 This research was performed in accordance with the laws, guidelines and ethical

210 standards of Iran, where the research was performed.

211 Author's contributions

212 RHH is the sole author. He carried out all analyses and drafted the manuscript. The

213 author read and approved the final manuscript.

214 Consent for publication

215 Not applicable.

216 Competing interests

217 The author declares that they have no competing interests

218

219 References

220 Askari, Y, Zobeiri, M \&Sohrabi, H, 2013, Comparison of five distance sampling methods

221 for estimating quantativechracteristics of Zagros forests. Iranian journal of forest and poplar

222 research, 21: 316-328.[In Persian]

223 Bonham, CD 2013, Measurements for Terrestrial Vegetation. New York, John Wiley \&

224 Sons, Inc.: 246. 
225 Borges Silva, L, Alves, M, Elias, RB \& Silva, L 2017. Compparison of T-square, point

226 centered quarter and N-tree sampling methods in Pittosporumundulatum invaded woodlands.

227 International Journal of Forestry Research, 2017: 2818132.

228 Cottam, G \& Curtis, JT 1954, The use of distance measures in phytosociological sampling 229 Ecology, 37:451-461.

230 Engeman, RM, Pank, LF, Sugihara, RT \&Dusenberry, RT 1994, A comparison of Plot-less

231 density estimators using Monte Carlo simulation. Journal of Ecology, 75:1769-1779.

232 Haidari, RH 2006, Study of Different Distance Sampling Methods in the Zagross Forests 233 Area(Kermanshah province), Ph.D. thesis in Forestry, Tehran University of IRAN. [In 234 Persian]

235 Haidari, RH 2008, Distance Sampling Method in Forest Inventory, Razi University Press, 236 IRAN. 132 pp. [In Persian]

237 Haidari, RH, Zobeiri, M, Namiranian, M \&Sobhani,H 2007, Application of T-square

238 sampling method in Zagross forests (Case Study: Kerman-shah province) - Iran. J. For.

239 Poplar Res. 15: 32-42. [In Persian]

240 Haidari, RH, Namiranian, M, Zobeiri, M \&Sobhani,H 2008, Sampling study of applicability

241 of point-center quarter method in Zagros Forests (Case Study: Kermanshah province)-

242 Journal of the Iranian Natural Res. 61(1): 85-97. [In Persian]

243 Kiani, B, Tabari, M, Fallah, A, Hosseini, SM \& In Parizi, M.-H 2013, A comparison of

244 distance sampling methods in Saxaul (Halloxylonammodendron (C.A. Mey Bunge) shrub-

245 lands. Pol. J. Ecol. 61(Batcheler, 1971):207-219. 
246 Krebs, CJ 1989, Ecological Methodology. Harper Collins: New York. 653 pp.

247 Krebs, CJ 2001, Programs for Ecological Methodology, 2th ed. Dept.of Zoology University

248 of British Colombia,Vancouver, B.C. Canada V6T 1Z4 (software version 6.0).

249 Mitchell, K 2007, Quantitative Analysis by the Point-Centered Quarter Method. Hobart and

250 William Smith Colleges.Geneva, NY 14456. mitchell@hws.edu

251 Moghadam, MR 2001, Quantative plant ecology. Tehran University press. 285pp. [In

252 Persian]

253 Namiranian, M 2010, Measurement of tree and forest biometry. Tehran University press.

254 620pp. [In Persian]

255 Picard, N, Kouyate, AM \&Dessard, H 2005, Tree density estimations using a distance

256 method in Mali Savanna. Journal of Tropical Forest Science, 31: 7-18.

257 Pollard, JH 1971, On distance estimators of density in randomly distributed forests.

258 Biometrics, 27(4): 991-1002. ISSN 0006341X. URLhttp://www.jstor.org/stable/2528833.

259 Safari, A 2010, Evaluation of Spatial distribution pattern of Quercuspersicaand

260 PistaciaatlanticaDesf. in Zagros Forest) case study: Bayangan Forests, Kermanshah). M.Sc.

261 thesis, Faculty of Natural Resources, University of Kurdistan, 83 pp.[In Persian]

262 Sheil, D, Ducey, MJ, Sidiyasa, K \& Sam-soedin, I 2003, A new type of sample unit for the

263 efficient assessment of diverse tree communities in complex forest landscapes. Journal of

264 Tropical Forest Science, 15:117-135.

265 Southwood,TRE\& Henderson, PA 2000, Ecological Methods. Blackwell science. 575 pp. 


\begin{tabular}{|c|c|c|c|c|}
\hline Equations & sign & $\begin{array}{l}\text { Estimated density in each sample } \\
\text { point }\left(\text { trees } / \mathrm{m}^{2}\right)\end{array}$ & $\begin{array}{c}\text { Mean estimated density in } n \\
\text { sample points }\left(\text { trees } / \mathrm{m}^{2}\right)\end{array}$ & Reference \\
\hline Cottam and & $\mathrm{N}_{\mathrm{CC}}$ & ------------ & $\widehat{\mathbf{N}}_{\mathrm{cc}}=1 /\left[\left(\sum \mathrm{r}_{\mathrm{ij}} / \mathbf{4 n}\right)^{\wedge} 2\right]$ & Cottam and Curtis, \\
\hline Curtis & & & & 1954 \\
\hline Pollard & $\mathrm{N}_{P}$ & ------------.- & $\widehat{\mathbf{N}}_{\mathrm{p}}=[4(4 n-1)] /\left[\pi *\left(\sum \mathbf{r}_{\mathrm{ij}}{ }^{\wedge} 2\right]\right.$ & Pollard,1971 \\
\hline Haidari et al. & $\mathrm{N}_{\mathrm{H}}$ & $\begin{array}{c}\hat{\lambda}_{i}=\left[\left(r_{i 1} r_{i 2} r_{i 3} r_{i 4}\right)^{\wedge} 2\right] /\left[\left(\sum r_{i j}\right.\right. \\
\left./ 4)^{\wedge} 10\right]\end{array}$ & $\widehat{\mathbf{N}}_{\mathbf{H} .}=\sum \widehat{\boldsymbol{\lambda}}_{\mathbf{i}} / \mathbf{n}$ & Haidari et al. 2008 \\
\hline Dalahoo1(New) & $\mathrm{N}_{\mathrm{D} 1}$ & $\hat{\lambda}_{i}=3.092 /\left[\pi *\left(\sum \mathbf{r}_{\mathrm{ij}} / 4\right)^{\wedge} 2\right]$ & $\widehat{\mathbf{N}}_{\mathbf{D} 1}=\sum \hat{\boldsymbol{\lambda}}_{\mathbf{i}} / \mathbf{n}$ & New \\
\hline Dalahoo2(New) & $\mathrm{N}_{\mathrm{D} 2}$ & $\hat{\lambda}_{i}=0.50255 / \sum \mathbf{r}_{\mathrm{ij}}$ & $\widehat{\mathbf{N}}_{\mathbf{D} 2}=\sum \hat{\boldsymbol{\lambda}}_{\mathbf{i}} / \mathbf{n}$ & New \\
\hline
\end{tabular}

Where Ncc, Np, $\mathrm{N}_{\mathrm{H}}, \mathrm{N}_{\mathrm{D} 1}$ and $\mathrm{N}_{\mathrm{D} 2}$ : Number per unit area by Cottam, G \& Curtis, JT (1954), Pollard, JH (1971), Haidari et al.(2007) and new formulas respectively. $\hat{\lambda}_{i}$ : density in each sample point $\left(\right.$ trees $/$ unite area), $\boldsymbol{r}_{\mathrm{ij}}=$

distance $(m)$ from pt to nearest individual trees in sampling point $(i)$ and in quadratej $(j=1,2,3$ and4): $\widehat{\mathbf{N}}_{\text {trees/ha }}=10000 * \widehat{\mathbf{N}}_{\mathbf{i}}, \widehat{\mathbf{N}}_{\mathbf{i}}=\widehat{\mathbf{N}}_{\text {cc }}, \widehat{\mathbf{N}}_{\mathbf{p}}, \widehat{\mathbf{N}}_{\mathbf{H}}, \widehat{\mathbf{N}}_{\text {D1 }}$ and $\widehat{\mathbf{N}}_{\text {D2 }}$

$\mathbf{n}=$ sample size

\section{7}

Table 2. Results of statistical recording

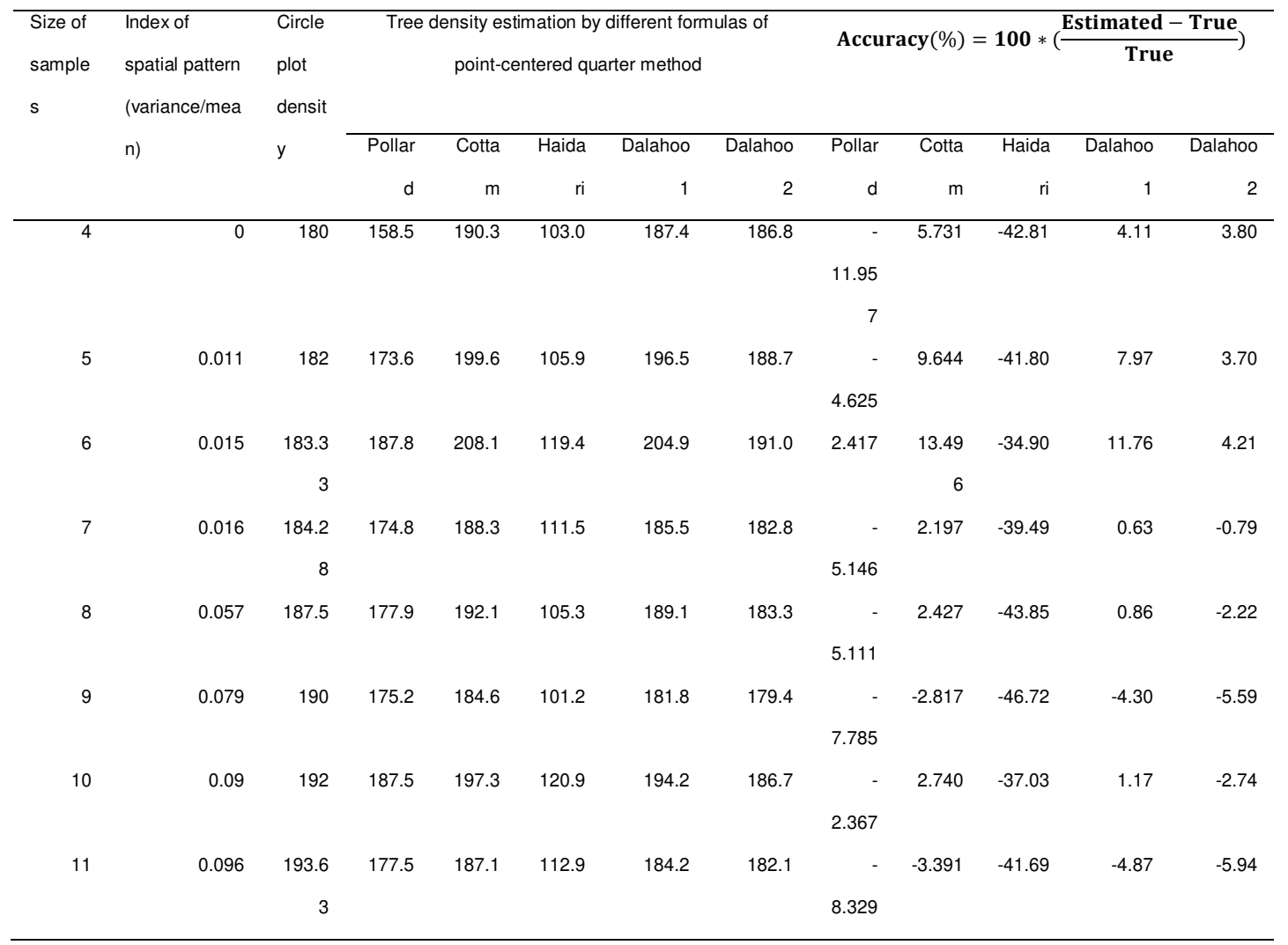




\begin{tabular}{|c|c|c|c|c|c|c|c|c|c|c|c|c|}
\hline \multirow[t]{2}{*}{12} & 0.112 & 191.6 & 188.2 & 198.4 & 134.0 & 195.4 & 188.9 & - & 3.511 & -30.07 & 1.93 & -1.44 \\
\hline & \multicolumn{3}{|c|}{7} & \multicolumn{9}{|c|}{1.798} \\
\hline \multirow[t]{2}{*}{13} & 0.145 & 189.2 & 174.7 & 189.1 & 124.6 & 186.2 & 184.7 & - & -0.088 & -34.18 & -1.62 & -2.39 \\
\hline & \multicolumn{3}{|c|}{3} & \multicolumn{9}{|c|}{7.683} \\
\hline \multirow[t]{2}{*}{14} & 0.168 & 187.1 & 180.5 & 194.9 & 125.0 & 191.9 & 187.2 & - & 4.144 & -33.21 & 2.55 & 0.01 \\
\hline & \multicolumn{3}{|c|}{4} & \multicolumn{9}{|c|}{3.573} \\
\hline \multirow[t]{3}{*}{15} & 0.208 & 184.6 & 165.3 & 176.7 & 120.0 & 174.0 & 181.3 & - & -4.339 & -35.04 & -5.80 & -1.80 \\
\hline & \multicolumn{3}{|c|}{7} & \multicolumn{9}{|c|}{10.51} \\
\hline & & & & \multicolumn{9}{|c|}{3} \\
\hline \multirow[t]{2}{*}{16} & 0.216 & 183.1 & 170.6 & 182.0 & 118.0 & 179.2 & 183.7 & - & -0.606 & -35.57 & -2.13 & 0.31 \\
\hline & \multicolumn{3}{|c|}{3} & \multicolumn{9}{|c|}{6.848} \\
\hline \multirow[t]{2}{*}{17} & 0.244 & 185.2 & 171.0 & 181.5 & 114.2 & 178.7 & 182.6 & - & -2.039 & -38.37 & -3.54 & -1.43 \\
\hline & \multicolumn{3}{|c|}{9} & & & & & 7.737 & & & & \\
\hline 18 & 0.295 & 182.7 & 175.6 & 186.4 & 114.7 & 183.6 & 184.8 & - & 1.998 & -37.24 & 0.44 & 1.13 \\
\hline & & 8 & & & & & & 3.924 & & & & \\
\hline 19 & 0.335 & 180.5 & 175.8 & 184.8 & 113.6 & 182.0 & 183.5 & - & 2.384 & -37.08 & 0.82 & 1.62 \\
\hline & & 3 & & & & & & 2.635 & & & & \\
\hline 20 & 0.367 & 178.5 & 179.5 & 187.4 & 117.8 & 184.6 & 184.2 & 0.560 & 4.998 & -34.03 & 3.39 & 3.19 \\
\hline 21 & 0.414 & 180.9 & 185.7 & 194.9 & 122.9 & 191.9 & 189.2 & 2.624 & 7.683 & -32.09 & 6.04 & 4.55 \\
\hline & & 5 & & & & & & & & & & \\
\hline 22 & 0.465 & 178.6 & 173.7 & 183.4 & 118.8 & 180.6 & 185.3 & - & 2.694 & -33.52 & 1.12 & 3.76 \\
\hline & & 3 & & & & & & 2.759 & & & & \\
\hline 23 & 0.559 & 181.7 & 173.7 & 182.6 & 117.1 & 179.8 & 184.3 & - & 0.476 & -35.58 & -1.06 & 1.42 \\
\hline & & 4 & & & & & & 4.447 & & & & \\
\hline 24 & 0.631 & 184.5 & 175.8 & 184.2 & 115.5 & 181.4 & 184.6 & - & -0.183 & -37.44 & -1.71 & -0.01 \\
\hline & & 8 & & & & & & 4.778 & & & & \\
\hline 25 & 0.677 & 182.4 & 174.4 & 183.5 & 111.6 & 180.7 & 183.7 & - & 0.607 & -38.84 & -0.93 & 0.70 \\
\hline & & & & & & & & 4.380 & & & & \\
\hline 26 & 0.765 & 185.3 & 174.8 & 183.7 & 108.5 & 180.9 & 183.2 & - & -0.915 & -41.47 & -2.43 & -1.16 \\
\hline & & 8 & & & & & & 5.683 & & & & \\
\hline 27 & 0.834 & 188.1 & 180.0 & 190.1 & 123.4 & 187.2 & 188.1 & - & 1.027 & -34.42 & -0.52 & -0.03 \\
\hline & & 5 & & & & & & 4.315 & & & & \\
\hline 28 & 0.903 & 185.7 & 179.6 & 188.7 & 121.7 & 185.8 & 187.0 & - & 1.602 & -34.47 & 0.05 & 0.68 \\
\hline & & 1 & & & & & & 3.298 & & & & \\
\hline 29 & 0.96 & 183.4 & 174.4 & 182.7 & 119.3 & 179.9 & 184.6 & - & -0.394 & -34.99 & -1.92 & 0.62 \\
\hline & & 5 & & & & & & 4.940 & & & & \\
\hline 30 & 1.05 & 186.3 & 178.9 & 188.9 & 120.2 & 186.0 & 189.5 & - & 1.355 & -35.49 & -0.19 & 1.73 \\
\hline & & 3 & & & & & & 4.006 & & & & \\
\hline 31 & 1.15 & 189.3 & 181.9 & 192.0 & 120.3 & 189.0 & 190.9 & - & 1.373 & -36.46 & -0.18 & 0.80 \\
\hline & & 5 & & & & & & 3.963 & & & & \\
\hline 32 & 1.2 & 191.8 & 185.3 & 195.1 & 127.5 & 192.1 & 192.2 & - & 1.679 & -33.58 & 0.12 & 0.19 \\
\hline & & 8 & & & & & & 3.426 & & & & \\
\hline 33 & 1.27 & 194.5 & 184.2 & 192.9 & 125.7 & 190.0 & 190.9 & - & -0.822 & -35.39 & -2.34 & -1.87 \\
\hline & & 5 & & & & & & 5.303 & & & & \\
\hline 34 & 1.35 & 197.3 & 188.2 & 197.6 & 135.7 & 194.5 & 193.8 & - & 0.104 & -31.24 & -1.43 & -1.78 \\
\hline & & 5 & & & & & & 4.613 & & & & \\
\hline 35 & 1.44 & 200.2 & 191.9 & 201.5 & 142.7 & 198.4 & 196.0 & - & 0.618 & -28.74 & -0.92 & -2.13 \\
\hline & & 6 & & & & & & 4.177 & & & & \\
\hline 36 & 1.56 & 197.5 & 190.6 & 200.8 & 139.2 & 197.7 & 195.2 & - & 1.658 & -29.51 & 0.10 & -1.16 \\
\hline & & & & & & & & 3.517 & & & & \\
\hline
\end{tabular}




\begin{tabular}{|c|c|c|c|c|c|c|c|c|c|c|c|c|}
\hline \multirow[t]{2}{*}{37} & 1.73 & 194.3 & 182.8 & 191.8 & 137.0 & 188.9 & 192.5 & - & -1.274 & -29.49 & $\begin{array}{l}-2.78 \\
\end{array}$ & -0.92 \\
\hline & \multicolumn{3}{|c|}{2} & \multicolumn{9}{|c|}{5.936} \\
\hline \multirow[t]{2}{*}{38} & 1.84 & 197.3 & 187.2 & 198.2 & 165.3 & 195.2 & 199.4 & - & 0.431 & -16.27 & -1.10 & 1.02 \\
\hline & \multicolumn{3}{|c|}{6} & \multicolumn{9}{|c|}{5.157} \\
\hline \multirow[t]{2}{*}{39} & 1.96 & 200.5 & 188.8 & 199.6 & 162.6 & 196.6 & 199.5 & - & -0.442 & -18.90 & -1.96 & -0.49 \\
\hline & \multicolumn{3}{|c|}{1} & \multicolumn{9}{|c|}{5.859} \\
\hline \multirow[t]{2}{*}{40} & 2.15 & 197.2 & 187.6 & 197.8 & 159.6 & 194.8 & 198.3 & - & 0.266 & -19.08 & -1.27 & 0.52 \\
\hline & \multicolumn{3}{|c|}{5} & \multicolumn{9}{|c|}{4.899} \\
\hline
\end{tabular}

269

270

Table3. Comparison results of different formulas of point-centered quarter method with circle plot

\section{Paired Differences}

$95 \%$ Confidence

Pair

Std. Std. Interval of the

Deviatio Error Difference

Sig. (2-

\begin{tabular}{|c|c|c|c|c|c|c|c|c|}
\hline & Mean & $\mathrm{n}$ & Mean & \multicolumn{2}{|l|}{ J ower } & $\mathrm{t}$ & df & tailed) \\
\hline Circle - Pollard & 8.655 & 5.342 & 0.878 & 6.874 & 10.436 & 9.856 & 36 & $.000^{* * *}$ \\
\hline Circle - Cottam & -2.842 & 6.329 & 1.04 & -4.952 & -0.732 & -2.731 & 36 & $.010^{* * *}$ \\
\hline Circle - Haidari & 64.788 & 11.353 & 1.866 & 61.003 & 68.574 & 34.711 & 36 & $.000^{* *}$ \\
\hline Circle - Dalahoo1 & 0.075 & 6.269 & 1.031 & -2.015 & 2.165 & 0.073 & 36 & $.942^{\mathrm{ns}}$ \\
\hline Circle - Dalahoo2 & 0.083 & 4.517 & 0.743 & -1.423 & 1.589 & 0.111 & 36 & $.912^{\mathrm{ns}}$ \\
\hline Pollard - Cottam & -11.497 & 4.858 & 0.799 & -13.117 & -9.877 & -14.396 & 36 & $.000^{* *}$ \\
\hline Pollard -Haidari & -56.133 & 11.403 & 1.875 & -59.935 & -52.331 & -29.942 & 36 & $.000^{* *}$ \\
\hline Pollard -Dalahoo1 & 8.58 & 4.829 & 0.794 & 6.97 & 10.19 & 10.808 & 36 & $.000^{* *}$ \\
\hline Pollard - Dalahoo2 & -8.573 & 4.967 & 0.817 & -10.229 & -6.917 & -10.498 & 36 & $.000^{* *}$ \\
\hline Cottam -Haidari & -67.63 & 12.894 & 2.12 & -71.929 & -63.331 & -31.906 & 36 & $.000^{* *}$ \\
\hline Cottam -Dalahoo1 & -2.917 & 0.108 & 0.018 & -2.953 & -2.881 & -163.876 & 36 & $.000^{* *}$ \\
\hline Cottam - Dalahoo2 & 2.925 & 4.478 & 0.736 & 1.432 & 4.418 & 3.973 & 36 & $.000^{* * *}$ \\
\hline Haidari - Dalahoo1 & -64.713 & 12.903 & 2.121 & -69.015 & -60.411 & -30.506 & 36 & $.000^{* *}$ \\
\hline Haidari - Dalahoo2 & -64.706 & 10.978 & 1.805 & -68.366 & -61.045 & -35.851 & 36 & $.000^{* *}$ \\
\hline Dalahoo1 & & & & & & & & \\
\hline Dalahoo2 & 0.007 & 4.405 & 0.724 & -1.461 & 1.476 & 0.01 & 36 & $.992^{\mathrm{ns}}$ \\
\hline
\end{tabular}




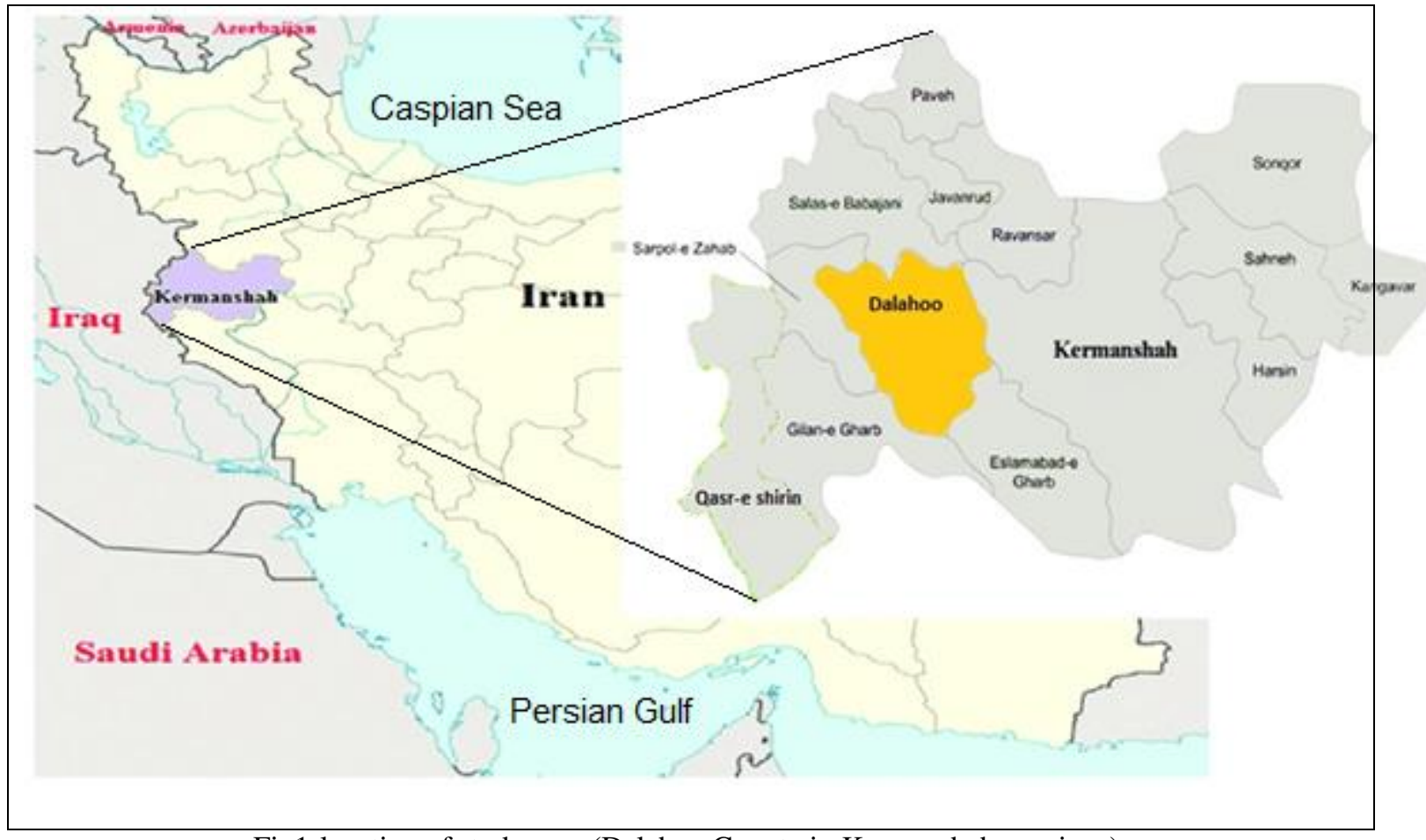

Fig1-location of study area (Dalahoo County in Kermanshah province).

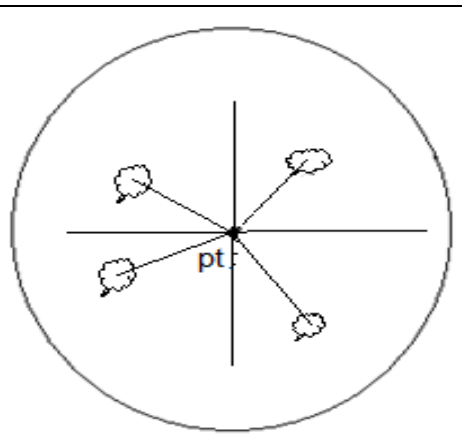

Fig. 2. Position of point-centered quarter method in the circle plot 


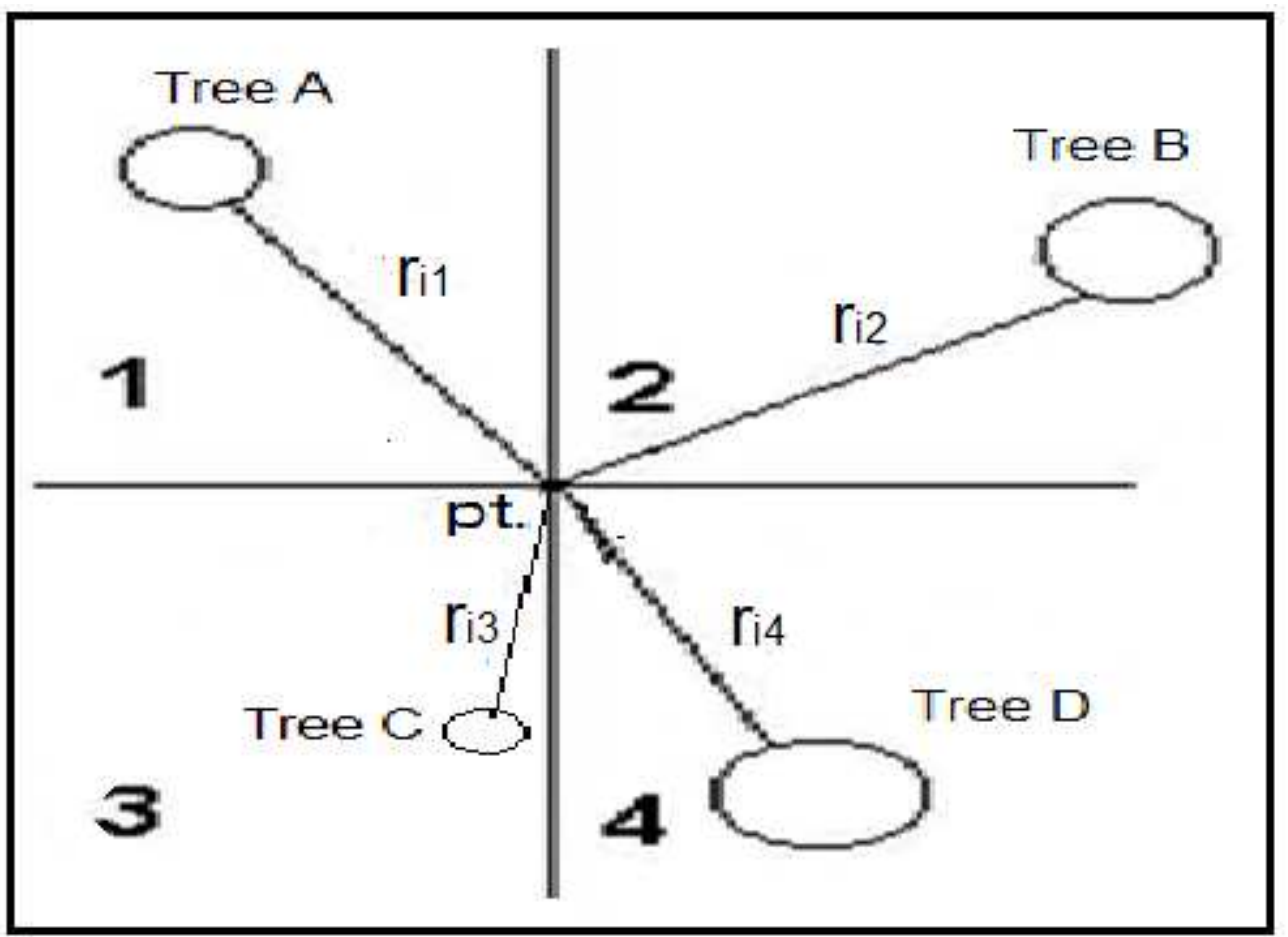

Fig. 3. point-centered quarter method

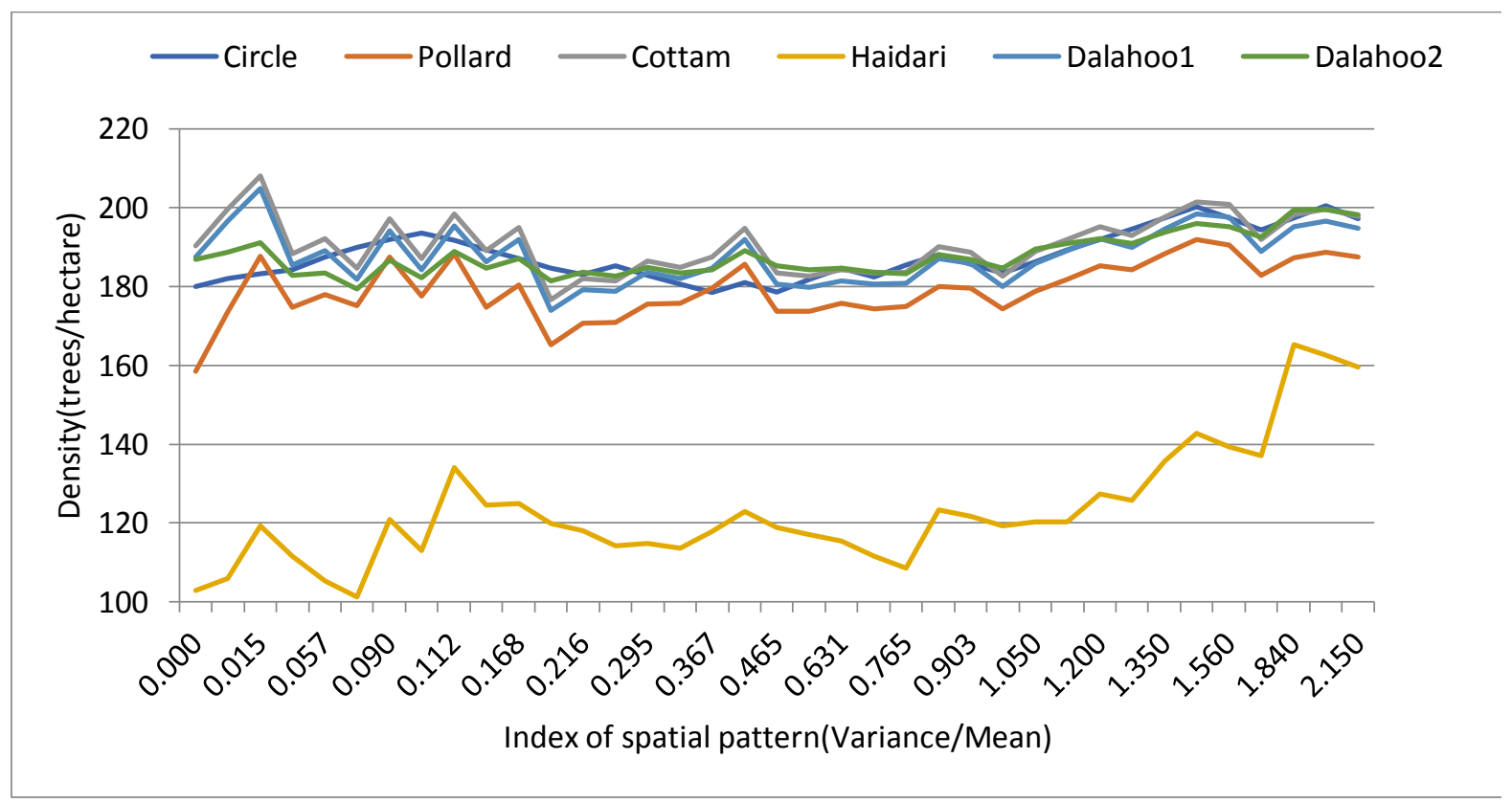

Fig. 4. The relationship between variance/mean ratio and estimated number of trees per hectare using different equations 


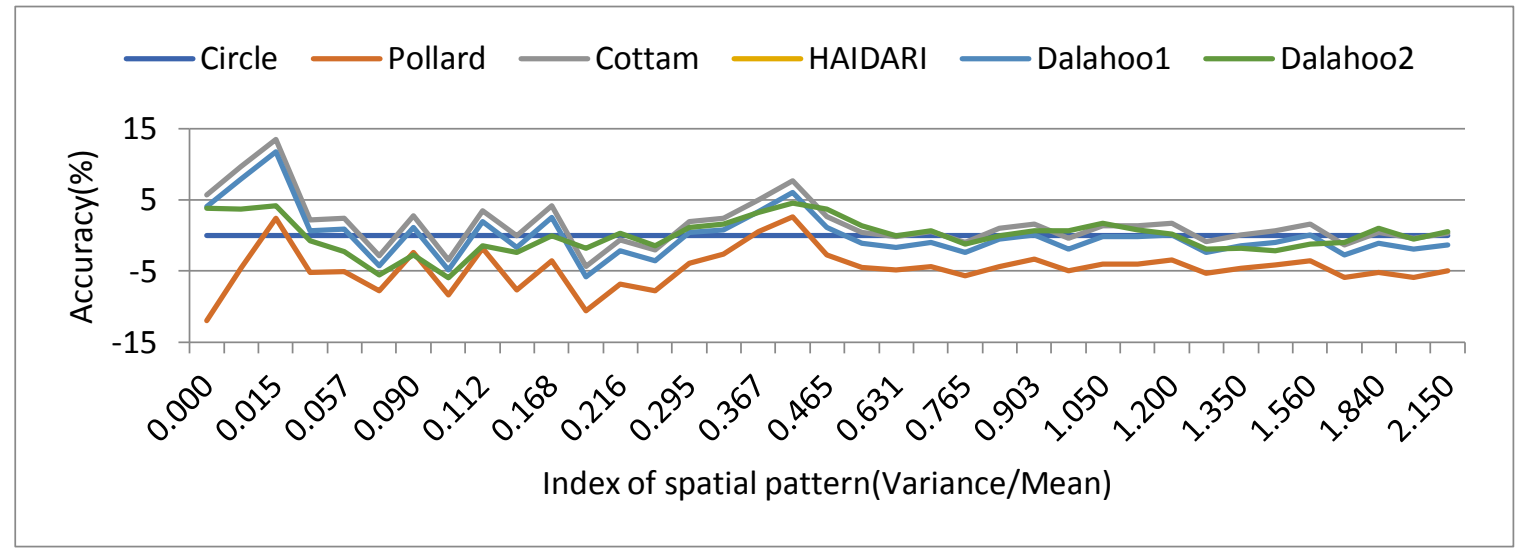

Fig. 5. The relationship between the Index of spatial pattern(variance/mean) with accuracy of estimate the number of trees per hectare with different formulas 
Figures

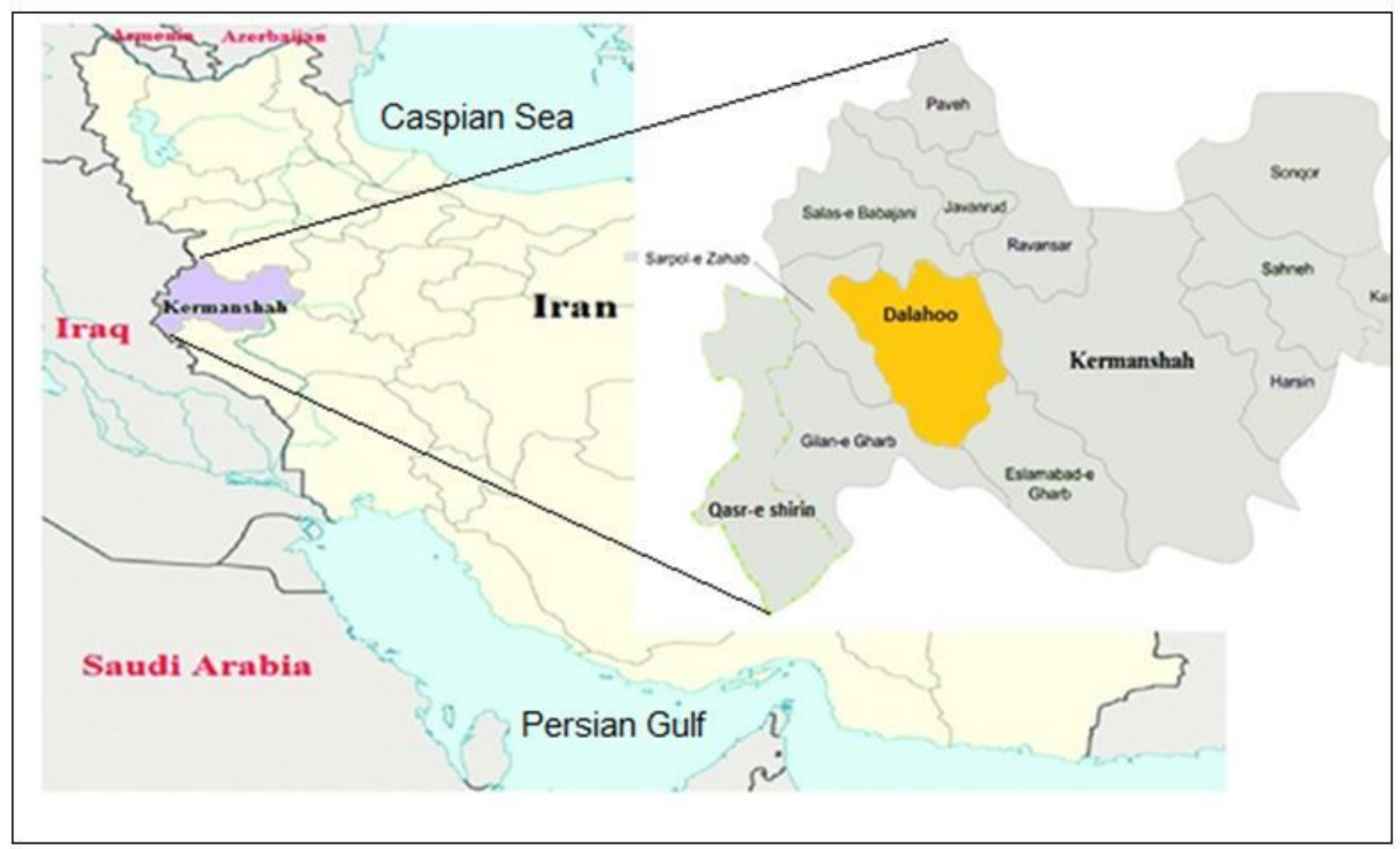

Figure 1

location of study area (Dalahoo County in Kermanshah province). 


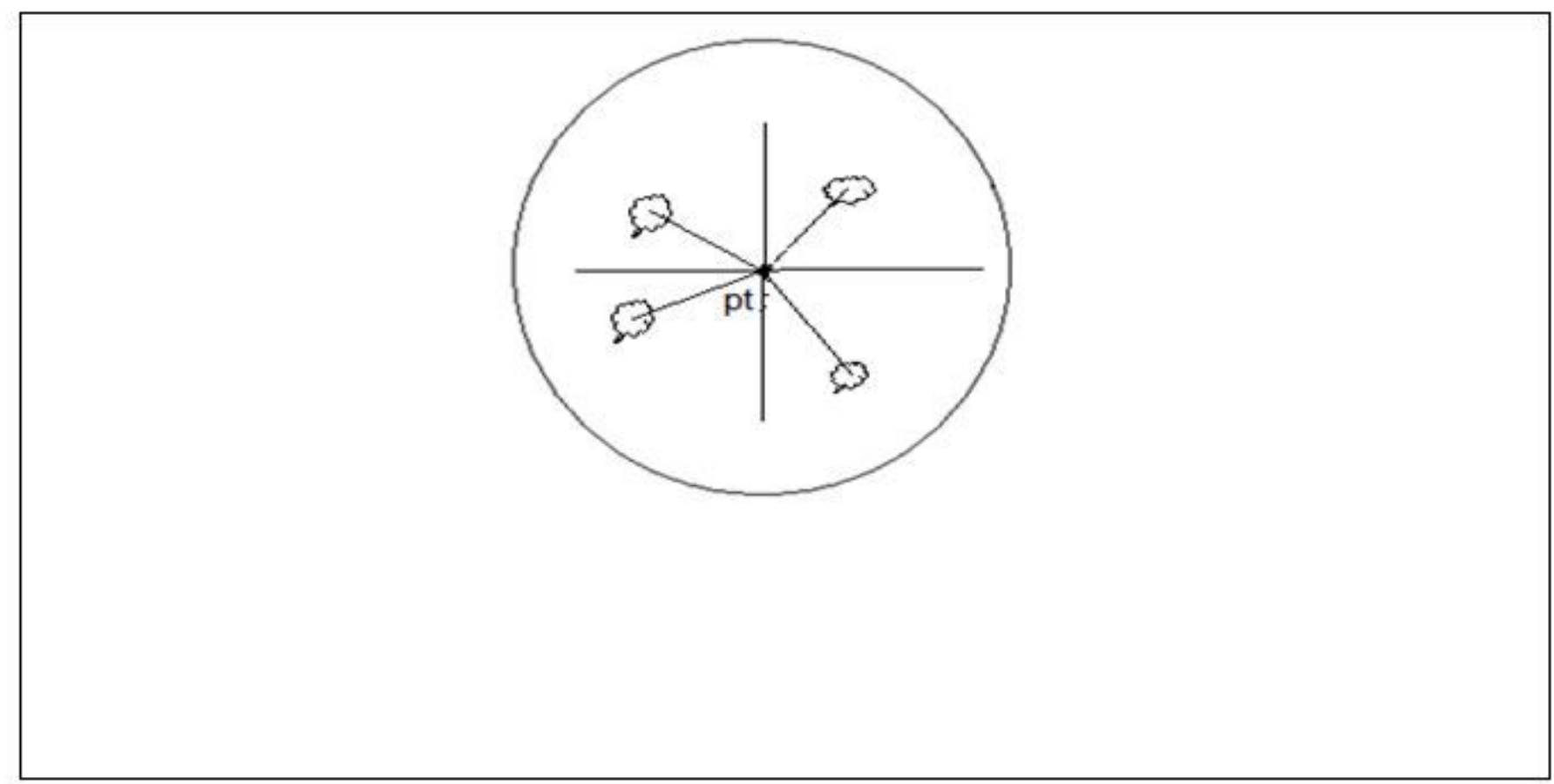

Figure 2

Position of point-centered quarter method in the circle plot 


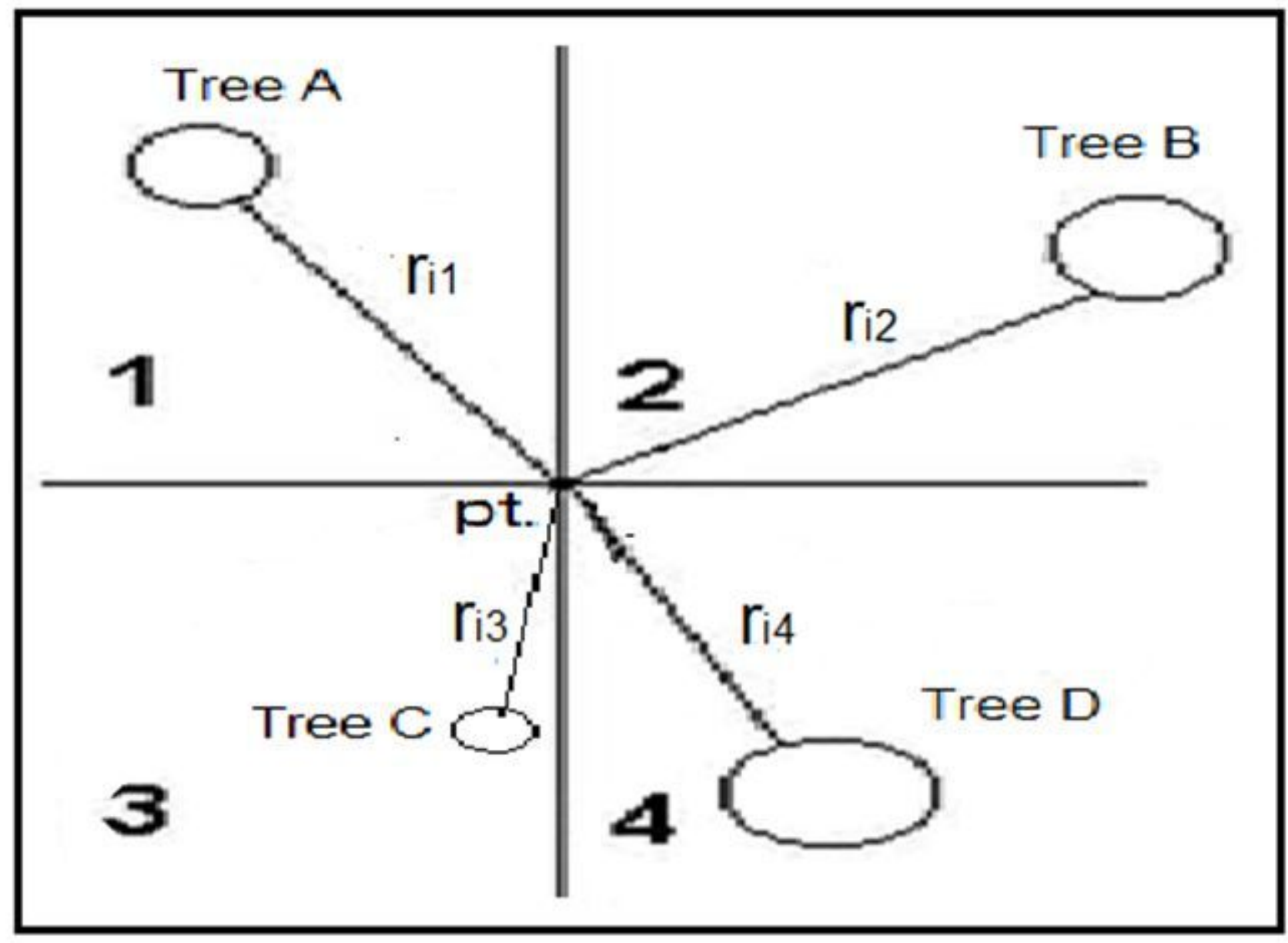

Figure 3

point-centered quarter method 


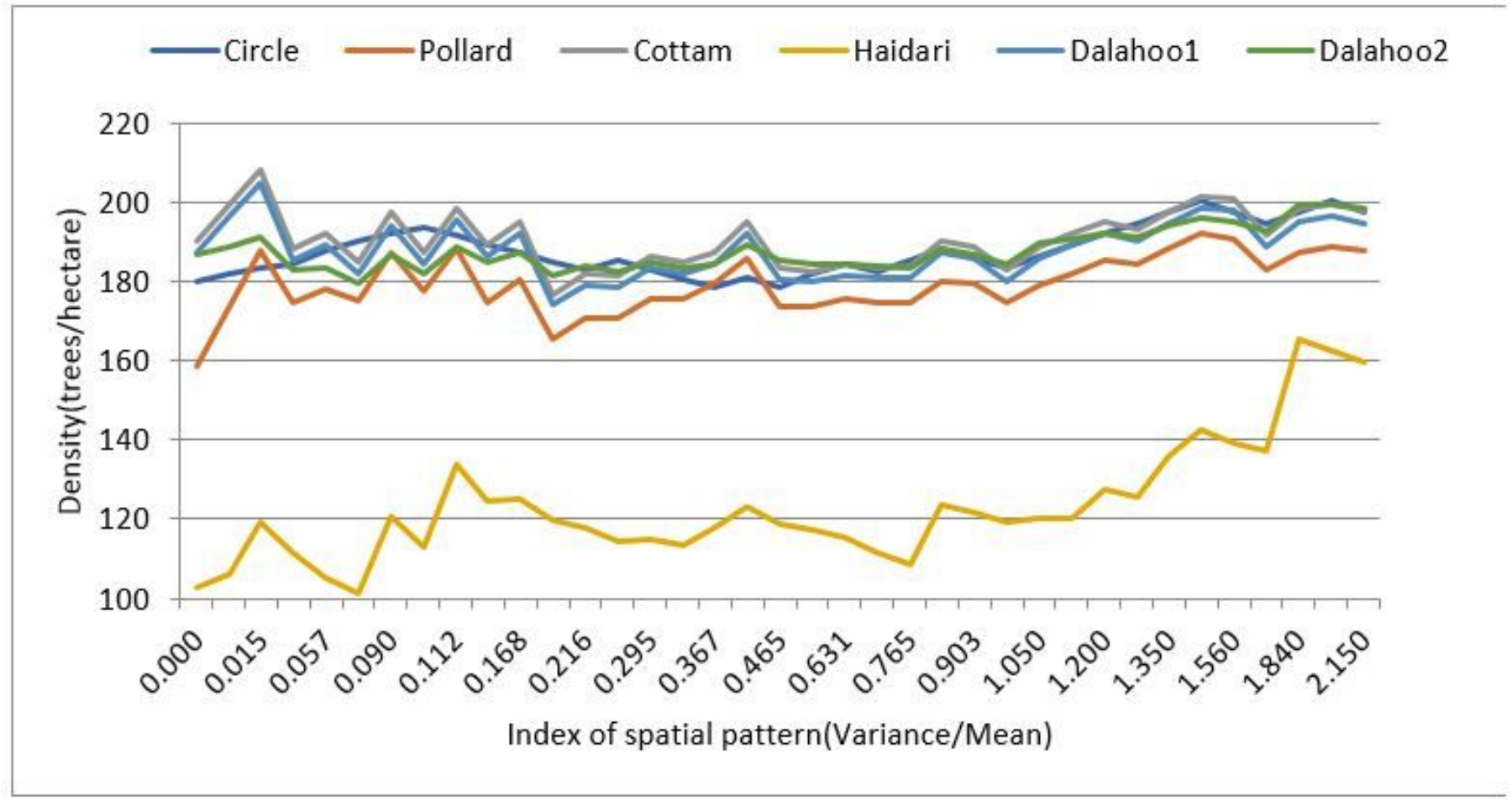

\section{Figure 4}

The relationship between variance/mean ratio and estimated number of trees per hectare using different equations

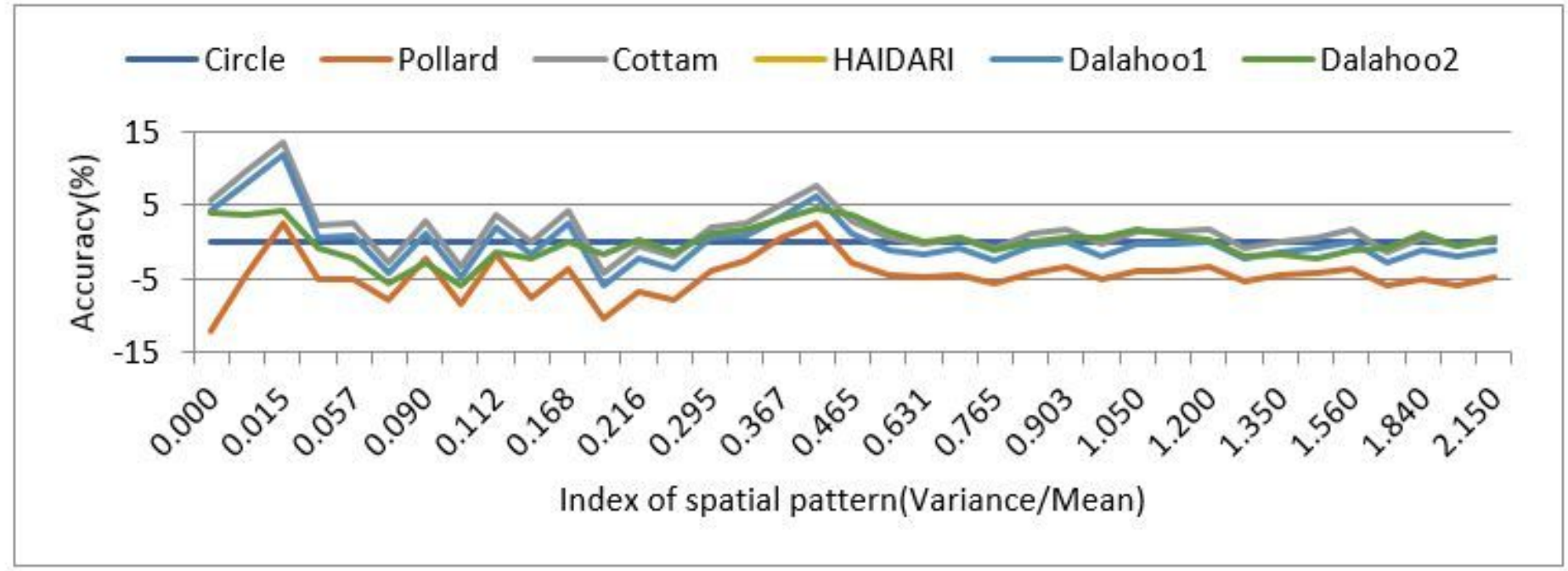

\section{Figure 5}

The relationship between the Index of spatial pattern(variance/mean) with accuracy of estimate the number of trees per hectare with different formulas 